\section{Income transfer policies and the impacts on the immunization of children: the Bolsa Família Program}

\author{
Programas de transferência de renda e impactos na \\ imunização das crianças: o Programa Bolsa Família
}

Mônica Viegas Andrade 1

Flávia Chein 1,2

Laetícia Rodrigues de Souza ${ }^{1}$

Jaume Puig-Junoy 3

\footnotetext{
${ }^{1}$ Faculdade de Ciências Econômicas, Universidade Federal de Minas Gerais, Belo Horizonte, Brasil.

2 Universidade Federal de Juiz de Fora, Juiz de Fora, Brasil.

${ }^{3}$ Universitat Pompeu Fabra, Barcelona, España.

Correspondence M. V. Andrade Centro de Desenvolvimento e Planejamento Regional, Faculdade de Ciências Econômicas, Universidade Federal de Minas Gerais. Av. Antonio Carlos 6627 Belo Horizonte, $M G$ 31270-901, Brasil. mviegas@cedeplar.ufmg.br
}

\section{Abstract}

This paper investigates the impact of the Bolsa Familia Program on the immunization of children from 0 to 6 years of age in Brazil and its regions. The Bolsa Família program is a conditional cash transfer program. One of its conditionalities is the compliance of children with the immunization schedule ordered by the Ministry of Health. The evaluation was performed using the Propensity Score Matching technique. We used data from a survey conducted in 2005 evaluating the program - Pesquisa de Avaliação de Impacto do Programa Bolsa Família. The main findings suggest that the Bolsa Família Program does not affect the immunization status of children.

Income; Public Policies; Immunization; Child

\section{Introduction}

An important dimension of health status is preventive healthcare and the promotion of health. The health condition of an individual can be seen as a capital stock, subject to a depreciation rate and stochastic shocks. Such stochastic shocks have a random component as well as a deterministic component which is mainly associated with life cycle and with personal habits. In a way, measures towards health prevention and/ or promotion can affect the probability of shocks in the health condition. Immunization is one of the most efficient forms of preventive health, especially when a high coverage rate is attained for an entire population. In Brazil, immunization campaigns are a priority in terms of public policies, and the Brazilian Ministry of Health 1 has a defined schedule for the free immunization for children 0 to 6 years of age. Despite the massive free immunization campaigns, there are still segments of the population - particularly those with low incomes - that do not follow the established immunization schedule. Some factors can explain this observation such as the lack of information about the benefits of immunization, transportation costs to healthcare centers and opportunity costs as the time allocated for immunization represents a reduction in working time 2,3,4,5,6.

One way for the government to give direct incentives for immunization and preventive 
healthcare within low income groups is to establish conditionalities in cash transfer programs in a way that families receive the cash payment only if they comply with certain requirements. Conditional Cash Transfer Programs (CCT) are quite widespread in less developed countries, particularly in Latin America. Notable among them are Oportunidades in Mexico (previously Progresa), Red de Protección Social in Nicaragua, Programa de Asignácion Familiar in Honduras, Familias en Acción in Colombia, Subsidio Único Familiar in Chile and the Program of Advancement through Health and Education in Jamaica 7. Similar programs are also being implemented in Sub-Saharan Africa, Bangladesh and Nepal 8.

There is evidence that CCT programs have positive impacts on health indicators 9 . Most of the empirical evidence comes from the evaluative analysis of Oportunidades in Mexico which is now the benchmark of CCT programs. In Oportunidades, healthcare and educational components are strongly enforced. This program has efficient monitoring as it has developed a modern information system that allows for follow-up on the visits of beneficiaries 10. Every two months, families receive a cash transfer, though only if the conditionalities are met. According to Fernaud et al. 10 only $1 \%$ of households are denied the cash transfer for non-compliance.

From a theoretical approach, conditionalities associated with cash transfer programs are efficient mechanisms to attain better allocation of human capital investment by families only if the income effect is transformed into a price effect 7 . This transformation occurs only if conditionalities are monitored and verified.

The aim of this paper is to analyze the effects of the Bolsa Família Program on the immunization of children, aged 0 to 6 years, who live in households covered by the program through the use of a baseline survey conducted in 2005 . We use the Propensity Score Matching method to investigate immunization differentials between children living in households enrolled in the Bolsa Família Program and children of eligible families who do not receive the benefits. We also compare the profiles of beneficiaries and nonbeneficiaries with regards to their municipalities of residence and household characteristics.

The Bolsa Família Program is now the biggest CCT program in the world. It covers approximately 11 million households reaching 45 million individuals. In order for the benefits to be received by the household, it must keep their school-age children and teenagers enrolled in school and comply with basic healthcare measures such as follow-up on the immunization schedule for children aged 0 to 6 years, as well as keep up with pre- and post-natal agendas for pregnant women and breastfeeding mothers. In contrast to Oportunidades, in 2005, the Bolsa Família Program presented a very low percentage of families with monitored healthcare indicators.

\section{The Bolsa Família Program}

The Bolsa Família Program, created in 2003, is a CCT program for poor families, aiming to promote immediate poverty alleviation through direct income transfers. It also aims to break the intergenerational poverty cycle through conditionalities which reinforce the exercise of social rights in areas of healthcare and education, potentially allowing for the fighting of future poverty by investing in the development of human capital. The program consists of the integration of existing conditional cash transfer programs in Brazil, namely: Auxilio Gás, Bolsa Alimentação, Cartão Alimentação and Bolsa Escola. Recent studies 11,12,13 highlight the potential effects of income transfer programs on the reduction of poverty and inequality in Brazil, thereby stressing the importance of such policies. The eligibility criteria of the Bolsa Família Program were defined in two contexts in 2005: (1) families with income per capita below $\mathrm{R} \$ 100.00$ (poverty line), with children under the age of 15 or pregnant women; (2) families with income per capita below $\mathrm{R} \$ 50.00$ (extreme poverty), with or without children. For families in extreme poverty, the benefits begin at a basic value of $\mathrm{R} \$ 50.00$ for those without children, pregnant women or breastfeeding mothers, and add a variable amount of $\mathrm{R} \$ 15.00$ for each child, up to a total of three. For families in poverty, the value of the benefit corresponds only to the variable portion. Currently, the program covers approximately 11 million households which represent almost 45 million people, or $25 \%$ of the Brazilian population. Since the creation of the program in 2003, expansion of the enrolled population has occurred quite quickly though 2004 was the period when expansion was at its highest 14 .

The Bolsa Família Program establishes conditionalities on the utilization of healthcare services and attendance at school. Once a family enrolls in the Bolsa Família Program, it is supposed to keep their school-age children and teenagers in school, in addition to complying with basic healthcare measures such as following the immunization schedule for children between 0 and 6 years of age and keeping up with pre- and post-natal agendas for pregnant women and breastfeeding mothers. Regarding attendance to school, in 2005, these conditionalities were verified by proper schools. Each school was respon- 
sible for sending the attendance records of the Bolsa Família Program beneficiaries to the Brazilian Ministry of Social Development. Education conditionalities began to be monitored in 2001 when the Bolsa Escola Program was launched. On the other hand, health conditionalities depend upon access to healthcare services. Beneficiaries of the Bolsa Família Program are supposed to be visited periodically by community health agents who are responsible for collecting information and sending these records to local health authorities. Health monitoring is recorded each semester and, as emphasized by Lindert et al. 15 , is much more complex than education.

Official data about conditionality monitoring evidence a strong difference between healthcare and education monitoring. In 2005, a small percentage of households had their health status monitored: in the first semester only $6 \%$ and, in the second semester, $31 \%$, contrasting to education monitoring that covered almost $63 \%$ of the beneficiary households monitored in 2006 .

\section{Methodology}

\section{Database}

The database used in this paper comes from a survey conducted by the Regional Development and Planning Center (CEDEPLAR; Centro de Desenvolvimento e Planejamento Regional) 14 in November of 2005. The data collection and clearance were performed by a research team from the Brazilian Geography and Statistics Institute (IBGE; Instituto Brasileiro de Geografia e Estatística), in accordance with other Brazilian household surveys. The survey was conceived as the baseline of a longitudinal evaluation study of the Bolsa Família Program and was contracted by the Brazilian Ministry of Social Development in conjunction with the United Nations Development Program (UNDP). The questionnaire investigates household conditions, individual characteristics, family expenditures/consumption and social benefits. Although the aim of the survey was to evaluate the Bolsa Família Program, the sample was designed to be representative of all Brazilian social groups. This strategy was chosen in order to allow analysis of program impact on inequality and poverty. In general, the questionnaire was answered by an adult who gave information about all members of the household. The immunization information was collected by the interviewer who conducted the questionnaire, based on the immunization card.

The sample design of the Bolsa Família Program Research Project follows a stratified sam- pling procedure. The sample size was defined in order to obtain representativeness for three large areas of Brazil: the Northeastern Region (NE), the Southeastern and Southern Regions (SE-SUL), and the Northern and Central-Western Regions (NO-CO). The data collection process occurred in November of 2005. The total number of completed questionnaires collected during the field work was 14,022 . For the SE-SUL regions, 5,077 questionnaires were collected $(77.1 \%$ of the amount expected). The NE and NO-CO regions presented 4,713 and 4,232 questionnaires $(84.5 \%$ and $87.7 \%$ of what was expected), respectively.

According to the information obtained from the questionnaires, groups of households were classified in terms of eligibility and treatment status. The eligibility criteria for this study were the household per capita income and the presence of either children between 0 and 14 years of age or a pregnant woman. The definition of per capita income includes earnings from work, retirement compensation, pensions and alimony. According to the first criterion, the sample was restricted to the households in which the per capita income was equal or less than $\mathrm{R} \$ 200.00$, after deducting income from cash transfer programs. Even though the eligibility criteria of the Bolsa Família Program establishes $\mathrm{R} \$ 100.00$ as the upper income limit, we included households that received up to $\mathrm{R} \$ 200.00$, in order to have $90 \%$ of the Bolsa Família Program beneficiaries included in our evaluation. Eligible households, in turn, were divided into subgroups. The first one, called "Beneficiary", consisted of households that were currently receiving cash transfers from the Bolsa Família Program in 2005. The second group, called "Non-Beneficiary", was composed of households that had never received any type of cash transfer from public programs. The remaining sample consisted of households; (1) that participated in other social programs, such as Bolsa Escola and Bolsa Alimentação; (2) which had received income transfer from social programs in the past but no longer received it; (3) which had a per capita income above $\mathrm{R} \$ 200.00$; or (4) where there were no children or pregnant women.

In order to investigate the fulfillment of the conditionalities regarding child healthcare, the researcher asked for the immunization records for all the children aged 0 to 6 years of age in the household. Based on these records, the dates of each immunization were registered on the questionnaire. Overall, we collected information on the 14 vaccines defined in the Brazilian Ministry of Health immunization schedule.

We defined five outcome variables in order to evaluate the immunization differentials be- 
tween the treatment and comparison groups: (1) a dichotomous variable that received a value of one if the child's records were shown, and zero otherwise; (2) a dichotomous variable assessing if the child was on schedule, according to his/ her age, with the immunization calendar; (3) a dichotomous variable regarding whether the child had received at least $70 \%$ of the suggested vaccines, according to his/her age; (4) a dichotomous variable assessing if the child had received all of the mandatory shots for children under six months of age; (5) a dichotomous variable regarding whether the child had received at least $70 \%$ of the required vaccines for children under six months of age.

It is worth mentioning that, when a child enrolled in the Bolsa Família Program seeks healthcare services in a Health Center, he/she receives all vaccines that are necessary to update his/her immunization schedule. As such, even though there are children that were not born into the program, we could expect that, once a child is enrolled in the Bolsa Família Program, he/she should receive all delayed immunizations.

Indicators 4 and 5 attempt to observe the time/care effects as the mother spends more time with the children up to 6 months of age. Additionally, children receive ambulatory care more frequently during their first year of life, allowing for more effective monitoring of the immunization schedule.

The total number of children aged zero to six years was 9,852, including those children living in households with a per capita income above R\$200.00 per month. From this total, 1,143 were excluded due to having declared that they possessed the immunization card but not being able to show it during the interview. Our final sample consists of 8,709 children that validly possessed the card and 7,550 that had a valid immunization schedule on it.

We performed the impact analysis taking into account heterogeneity between Brazilian regions. In order to contemplate differences between age groups, we split the sample into two sub-samples: children aged 0 to 3 and children aged 4 to 6 . In these sub-samples, we did not consider regional analysis due to sample restraints.

\section{Empirical approach}

In the evaluation of the immunization status of children benefiting from Bolsa Família Program, only households included in the "Beneficiary" or in the "Non-Beneficiary" groups were considered. Following the standard evaluation method for social programs, we used the results of nonparticipants in order to estimate how the par- ticipating children would be had they not been enrolled in the program. The difference between the results of the "Beneficiary" group (participants) and the "Non-Beneficiary" groups (nonparticipants) can be seen as the estimate of the gross impact of the program.

However, since the implementation of the Bolsa Família Program did not take place randomly among the eligible families, so as to have an experimental design of the program, the results from non-participants may systematically differ from the participants' results had they not enrolled in the program. This can generate a selection bias in the impact estimates 16. Specifically, in our analysis, what type of bias can we expect? The question that should be answered is why an eligible household is not enrolled in the Bolsa Família Program. This may occur in three main situations: (1) the household is located in a city with a low level of program coverage; (2) lack of information about the program; (3) it was a household decision to not enroll in the Bolsa Família Program. The first case would not generate a bias in our analysis because it would be exogenous to our output variable. The second and third situations could cause a bias in our control group. The bias occurs in the second situation due to information/knowledge differences across households and in the third situation because the decision not to enroll can be related to the fulfillment of program conditionalities. However, compliance with healthcare conditionalities is not so costly as the children's immunization schedules can be updated in just a few visits to the health center. Furthermore, health conditionalities are only registered every six months in the Bolsa Família Program, so a household can only exit the program six months after non-compliance with the conditionalities. Therefore, if a household decided not to enroll in the Bolsa Família Program, we can infer that this decision was more related to education conditionalities than to healthcare conditionalities. We shall address both of these potential biases in our empirical test.

A starting point for the evaluation of social programs, the design of which is not experimental, is to assume that program participation is based only upon variables observed previous to treatment and that there is enough juxtaposition between the distribution of these variables for the "Beneficiary" and "Non-Beneficiary" groups 17. Under such hypotheses, similar individuals, in terms of these variables, are paired and the average difference between them is estimated.

Since the matching of individuals may become difficult if one considers a large number of observed characteristics (a vector with $x$ dimen- 
sions), Rosenbaum \& Rubin 18 proposed the socalled Propensity Score Matching (PSM) as a way to overcome the problem of multidimensionality in the observed characteristics. In PSM, matching is based on the probability of participation in the program, estimated from characteristics observed before the beginning of the treatment. In this manner, pairs of individuals from the "Beneficiary" and "Non-Beneficiary" groups are formed based upon similar propensity scores and, subsequently, the average difference between them is estimated.

The propensity score of the Bolsa Família Program was estimated using a probit model in which the household is the unit of analysis. The explanatory variables in the model are the characteristics which, by hypothesis, are relevant to determine the participation in the program and were not affected by treatment. We included variables both at the household and municipal levels. The inclusion of municipal variables aims to capture the extent of the program in previous periods as well as the degree of poverty and development of the municipality, under the hypothesis that households in municipalities where the program is more wide-ranging (i.e. the levels of poverty are higher and development is lower) there will exist greater probability of participation in the program. In this group of variables, we include: number of households with a per capita income under $\mathrm{R} \$ 100.00 /$ total number of households; number of families supported by the Bolsa Escola program in 2001/total number of families with a per capita income of up to $\mathrm{R} \$ 200.00$; total fecundity rate; infant mortality rate (per one thousand live births); percentage of people in subnormal households; average number of years of education in people aged 25 and over. The household variables capture characteristics of family composition such as parent's literacy and domestic infra-structure - taken as proxy variables for income and welfare before program implementation.

Once we calculate the propensity scores for each household, the information is added for each child aged 0 to 6 living in the household. Subsequently, it is necessary to use some matching technique. In this study, we used the Nearest Neighbor Matching (NNM) technique with replacement. In the NNM, for each child living in a household enrolled in the Bolsa Família Program, another child not participating in any social program (and with a similar propensity score) is found. Once the matching is done it is possible to estimate three different effects: (a) the average treatment effect on the treated (ATT); (b) the average effect on the controls (ATC); and (c) the average treatment effect (ATE). The average effect on the treated is the average of the differences between treated ("Beneficiary") children and their pairs; the average effect on the controls is the average of the differences between children in the control ("Non-Beneficiary") group and their pairs. Finally, the average treatment effect considers the average of the differences between all the children in "Beneficiary" and "Non-Beneficiary” groups and their respective pairs.

\section{Results}

\section{Descriptive statistics}

Table 1 demonstrates the proportion of children who presented the immunization card and the proportion of immunized children according to our immunization indicators. Around $85 \%$ of children in Brazil possess immunization cards and this proportion is not significantly different between participants and non-participants of the Bolsa Família Program. Among the regions, the Northeastern is the one which presented the lowest percentage - around $81 \%$ of the children aged 0 to 6 that were able to show the immunization card. It is worth noting the difference in the proportion of children with immunization on schedule as compared to the proportion of children possessing an immunization card. The former is around $77 \%$ whereas the latter is $85 \%$. In this case, there is a positive differential for the Southern/Southeastern region, where $80 \%$ of the children are on schedule with their immunization calendar. The lowest proportion appears in the Northeastern region, where this percentage is approximately $73 \%$. The data does not show significant differences here between treatment and comparison groups.

The third immunization indicator analyzed here is the proportion of children with at least $70 \%$ of vaccines on schedule. In this case, the percentages are higher: in Brazil, the average proportion is $94 \%$ (i.e. 17 percentage points above the percentage found when all the vaccines are considered). This proportion is also higher in some regions, with the Southeastern region presenting the highest level. Differences were not detected between "Beneficiary" and "Non-Beneficiary" groups.

Regarding the proportion of children on schedule with all the shots required up to six months of age, the proportions are quite high, around $90 \%$ in most cases, suggesting that the majority of the children had had these shots.

The analysis of the immunization rate across age groups (0-3 and 4-6) reveals some differences. Records regarding the possession of the 
Proportion of children aged 0 to 6 years that showed the immunization card and proportion of immunized children, by groups of comparison. Brazil and Regions, 2005 *.

\begin{tabular}{|c|c|c|c|c|c|c|c|c|c|c|c|c|}
\hline \multirow[t]{2}{*}{ Variable result } & \multicolumn{3}{|c|}{ Brazil } & \multicolumn{3}{|c|}{ Northeast } & \multicolumn{3}{|c|}{ North/Center-West } & \multicolumn{3}{|c|}{ Southeast/South } \\
\hline & B & NB & Total & B & NB & Total & B & NB & Total & B & NB & Total \\
\hline \multicolumn{13}{|l|}{ Vaccination on schedule } \\
\hline Total of children in the sample & 3,019 & 1,377 & 7,550 & 1,062 & 479 & 2,504 & 907 & 440 & 2,313 & 1,050 & 458 & 2,733 \\
\hline$\%$ children & 75.63 & 77.21 & 77.48 & 76.32 & 70.04 & 73.23 & 74.98 & 77.91 & 76.56 & 74.99 & 80.78 & 80.35 \\
\hline Standard error & 2.20 & 2.20 & 1.30 & 2.40 & 3.90 & 2.40 & 2.70 & 5.50 & 3.60 & 4.90 & 2.60 & 1.70 \\
\hline \multirow{2}{*}{\multicolumn{13}{|c|}{$\begin{array}{l}\text { All the shots required up to } 6 \\
\text { months of age on schedule ** }\end{array}$}} \\
\hline & & & & & & & & & & & & \\
\hline Total of children in the sample & 3,019 & 1,377 & 7,550 & 1,062 & 479 & 2,504 & 907 & 440 & 2,313 & 1,050 & 458 & 2,733 \\
\hline$\%$ children & 89.14 & 86.34 & 88.61 & 87.12 & 77.85 & 82.54 & 89.53 & 87.00 & 87.94 & 91.54 & 90.63 & 92.48 \\
\hline Standard error & 1.00 & 2.00 & 1.00 & 1.50 & 4.80 & 2.50 & 1.50 & 3.60 & 2.30 & 1.70 & 2.10 & 1.00 \\
\hline \multicolumn{13}{|l|}{$70 \%$ of vaccines on schedule } \\
\hline Total of children in the sample & 3,019 & 1,377 & 7,550 & 1,062 & 479 & 2,504 & 907 & 440 & 2,313 & 1,050 & 458 & 2,733 \\
\hline \% children & 94.05 & 92.59 & 93.97 & 91.93 & 88.50 & 91.26 & 94.63 & 93.02 & 93.28 & 96.53 & 94.61 & 95.84 \\
\hline Standard error & 0.70 & 2.00 & 0.80 & 1.30 & 3.30 & 1.30 & 1.10 & 2.30 & 1.50 & 0.90 & 2.30 & 1.00 \\
\hline \multicolumn{13}{|l|}{$70 \%$ of shots required up to 6} \\
\hline \multicolumn{13}{|l|}{ months of age on schedule ** } \\
\hline Total of children in the sample & 3,019 & 1,377 & 7,550 & 1,062 & 479 & 2,504 & 907 & 440 & 2,313 & 1,050 & 458 & 2,733 \\
\hline$\%$ children & 95.85 & 94.41 & 95.50 & 93.78 & 91.99 & 93.60 & 96.84 & 94.06 & 94.45 & 98.10 & 95.86 & 96.98 \\
\hline Standard error & 0.70 & 1.40 & 0.70 & 1.30 & 2.30 & 1.00 & 0.80 & 2.10 & 1.40 & 0.60 & 2.10 & 1.00 \\
\hline \multicolumn{13}{|l|}{ Possession of immunization card $\star \star \star$} \\
\hline Total of children in the sample & 3,431 & 1,613 & 8,709 & 1,199 & 552 & 2,870 & 1,063 & 532 & 2,767 & 1,169 & 529 & 3,072 \\
\hline \% children & 85.95 & 84.88 & 85.33 & 85.61 & 79.27 & 81.00 & 86.90 & 85.44 & 86.71 & 86.05 & 87.99 & 87.69 \\
\hline Standard error & 1.90 & 2.20 & 1.50 & 2.40 & 5.50 & 3.30 & 2.00 & 2.00 & 1.50 & 3.70 & 2.50 & 1.90 \\
\hline
\end{tabular}

B: "Beneficiary"; NB: "Non-Beneficiary".

Source: Centro de Desenvolvimento e Planejamento Regional/SCIENCE - Associação Científica 14.

* The estimates were calculated considering the research sample design;

** According to the National Immunization Program 2006, the required vaccines for children up to 6 months of age are BCG, 1st and 2nd doses of Anti-Polio, DPT and Hepatitis B;

*** Conditioned on being able to show it during the interview.

immunization card and vaccinations being on schedule suggest that, as children become older, mothers are less worried about immunization. The possession of the immunization card for children aged from 0 to 3 is around 10 percent lower than that of the children aged from 4 to 6 years. Considering only the shots required up to 6 months of age, immunization performance is better for children aged between 4 and 6 years. This probably occurs due to the number of times children visit ambulatory units: as children aged 4 to 6 are older, they had more opportunities to update the early immunization schedule.

\section{Estimation results}

The probit model used in the estimation of the propensity score presented a good fit in all es- timated models. The most relevant variables in explaining the probability of participation in the program are the proportion of households with a per capita income of up to $\mathrm{R} \$ 100.00$, the family composition and the household density. These three variables are associated with the eligibility conditions of the program: the first one can be interpreted as a proxy for the propensity of the municipality to receive the Bolsa Família program, whereas the household composition and household density probably reflect the presence of children in the household. The probit results for age sub-samples are very similar to the one estimated for the whole sample.

Figure 1 demonstrates the density function of the propensity score for the "Beneficiary" and "Non-Beneficiary" groups concerning children aged zero to six years. It can be observed that, 


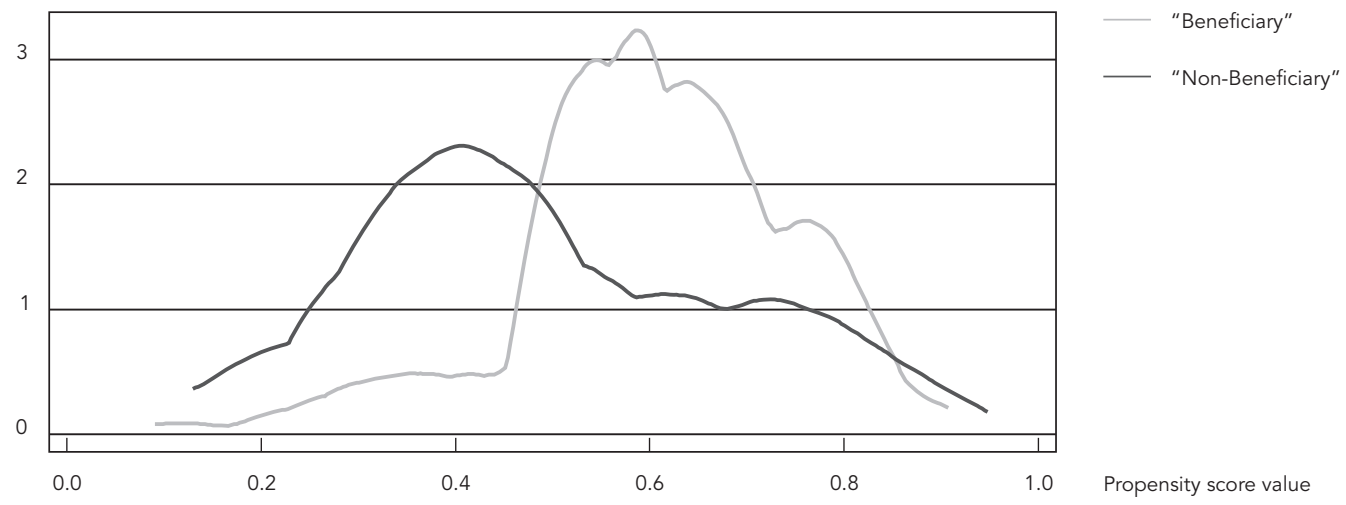

for lower propensity scores, there is a higher participation of households not enrolled in the Bolsa Família Program whereas, for values above 0.5, the proportion of enrolled households always exceed that of non-beneficiaries. Such densities reflect the focalization of the program.

In order to validate the quality of the propensity score estimation we present a graphical analysis of the per capita household income distribution, excluding the income received from the program according to the propensity score for treatment and comparison groups. One way of evaluating the quality of the propensity score estimation is to analyze the per capita household income distribution for both groups according to the propensity score values. The quality of the estimated propensity scores improves with greater juxtaposition between said distributions. Figure 2 shows income distribution by propensity scores and demonstrates that the expected behavior between the two groups in Brazil is quite similar. The per capita household income distribution is monotonically decreasing as the propensity score conversely increases (i.e. households with higher per capita household income have a lower probability of participating in the program). This is also observed among the Brazilian regions.

Another way to test the quality of matching is the comparison of averages of the co-variates included in the propensity score estimation, before and after the matching between "Beneficiary" and "Non-Beneficiary" groups in Brazil. The difference between averages of "Beneficiary" and "Non-Beneficiary" groups shows that matching has nearly no effect in making the groups more alike. All the significant differences before matching were maintained. In part, this may be explained by the reduced number of observations. In the case of Brazil, the sample in the "Non-Beneficiary" group is approximately one third of the sample in the "Beneficiary" group. The quality of matching depends on the number of "Non-Beneficiary" individuals. Such a reduced sample in the "Non-Beneficiary" group is a consequence of the expansion process and universalization of the program, especially from 2004 onwards, before the research data was collected. This is a restriction that cannot be overcome by the use of other evaluation techniques. The difficulty is that the evaluation design was proposed after program implementation.

The largest differences are found for municipal variables (infant mortality rate, percentage of households with a per capita income of less than $\mathrm{R} \$ 100.00$ ), for education variables of the guardians, and for certain household infrastructure variables. The analysis of these averages suggests that participating children live in less developed municipalities, in more precarious households and with less educated guardians.

Table 2 demonstrates the results of the average treatment effect for the "Beneficiary" children (ATT), for children in the "Non-Beneficiary" group (ATC) and for all the children in the sample (ATE). In all the cases, the sample weights of the children were considered for the estimation of the average differences between the pairs of children.

The results demonstrated in Table 3 suggest that inclusion in the Bolsa Família Program did 


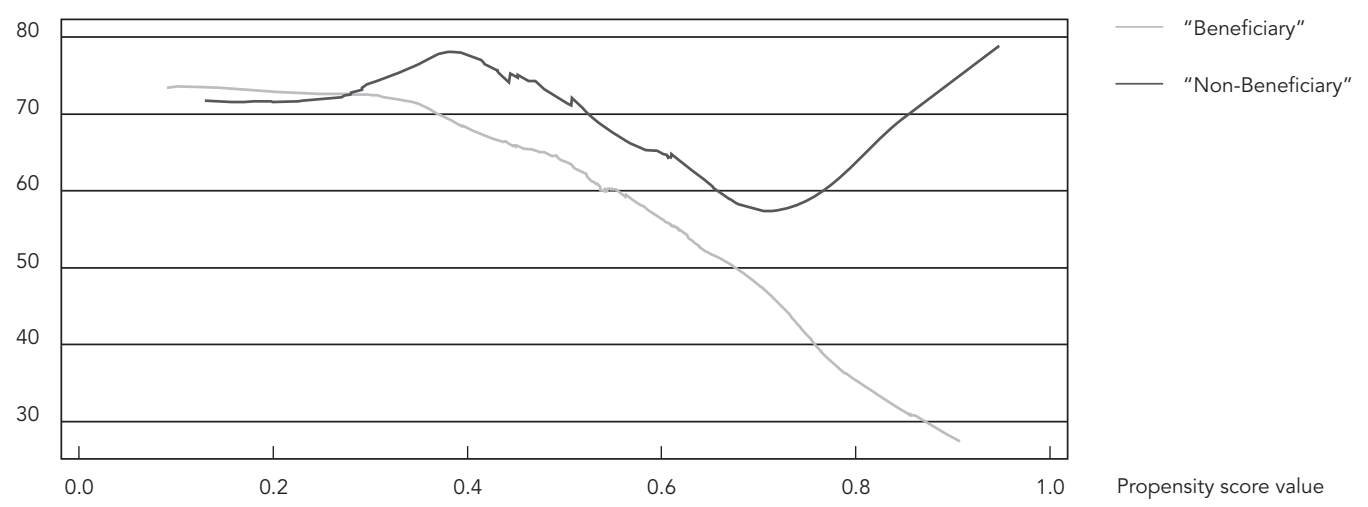

not affect the immunization status of children aged 0 to 6 years in 2005, using the assumption that the two groups are completely equal, except in relation to participation in the program.

Effects of the Bolsa Família Program on the immunization of children aged 0 to 6 were found only in the Southeastern/Southern region although said effects were of little significance and appear only for the vaccination-on-schedule indicator. This result corroborates the descriptive analysis. The results from Table 3 also suggest that, on average, the effect of the Bolsa Família Program represents a $7 \%$ increase in immunization, with $10 \%$ being significant in this region.

\section{Discussion}

In this paper, we investigated the impact of the Bolsa Família Program on the immunization of children aged 0 to 6 years of age in Brazil and its regions. The main results indicate that the program did not affect the immunization status of the children in 2005, when the monitoring of health conditionalities was still being implemented. Official data points to a strong increase in the percentage of beneficiaries covered by health monitoring in the following years. As such, this paper represents a baseline analysis for the purpose of understanding changes in the monitoring conditions.

The results obtained in this project are very different from those observed in relation to Oportunidades in Mexico. According to Gertler 9, the Mexican Program demonstrated clear, positive effects on child health, including a reduction in the illness rate during the first six months of life. However, in this case, it is known that conditionalities were extremely well-verified. For instance, children aged from 24 to 60 months were required to attend nutrition monitoring clinics every four months and obtain nutrition supplements when found to be underweight. In addition to the conditionalities, the program also requires the individuals to engage in preventive health and nutritional activities. In Brazil, official data points out that health conditionalities were not audited in 2005. As such, one contribution of this evaluation is to provide evidence of child health impacts, specifically immunization, in the context of a low level of monitoring conditionalities. This conclusion reinforces the need to investigate the reasons for non-compliance with the program conditionalities and the supervision costs associated with such public policy strategies.

In this paper we analyze three health outcomes regarding child immunization: possession of the immunization card, the proportion of children with immunization on-schedule and proportion of children with at least $70 \%$ of the vaccines on-schedule. The descriptive analysis of immunization indicators shows that, despite the vaccination campaigns and intensification of basic and preventive healthcare over the past 10 years, the level of immunization is still not universal among the poorest citizens in Brazil. The comparisons of the Bolsa Família Program beneficiaries and non-beneficiaries showed that there are no statistical differences in immunization coverage. Despite these similarities, the immu- 
Average effect of the Bolsa Família Program on the immunization of children aged 0 to 6 years. Brazil and Regions, 2005.

\begin{tabular}{|c|c|c|c|c|c|c|}
\hline \multirow[t]{4}{*}{ Result variable } & \multicolumn{3}{|c|}{ Brazil } & \multicolumn{3}{|c|}{ Regions } \\
\hline & & & & Northeast & North/ & Southeast \\
\hline & \multicolumn{6}{|c|}{ Children aged } \\
\hline & $0-3$ & $4-6$ & $0-6$ & & $0-6$ & \\
\hline \multicolumn{7}{|l|}{ Vaccination on schedule } \\
\hline \multirow[t]{2}{*}{ ATT } & -0.004 & -0.022 & -0.019 & 0.008 & -0.007 & 0.005 \\
\hline & $(0.038)$ & $(0.047)$ & $(0.031)$ & $(0.045)$ & $(0.039)$ & $(0.058)$ \\
\hline \multirow[t]{2}{*}{ ATC } & -0.051 & 0.049 & 0.055 & 0.059 & 0.037 & 0.102 * \\
\hline & $(0.053)$ & $(0.053)$ & $(0.039)$ & $(0.070)$ & $(0.069)$ & $(0.053)$ \\
\hline \multirow[t]{2}{*}{ ATE } & -0.037 & 0.018 & 0.029 & 0.034 & 0.026 & 0.074 * \\
\hline & $(0.040)$ & $(0.039)$ & $(0.029)$ & $(0.043)$ & $(0.054)$ & $(0.045)$ \\
\hline \multicolumn{7}{|c|}{$\begin{array}{l}\text { All the shots required up to } 6 \\
\text { months of age on schedule }\end{array}$} \\
\hline \multicolumn{7}{|c|}{ months of age on schedule } \\
\hline \multirow[t]{2}{*}{ ATT } & 0.001 & -0.018 & 0.013 & 0.038 & 0.009 & 0.036 \\
\hline & $(0.034)$ & $(0.021)$ & $(0.023)$ & $(0.038)$ & $(0.030)$ & $(0.040)$ \\
\hline \multirow[t]{2}{*}{ ATC } & -0.044 & 0.035 & 0.044 & 0.019 & 0.044 & 0.052 \\
\hline & $(0.048)$ & $(0.029)$ & $(0.031)$ & $(0.066)$ & $(0.053)$ & $(0.038)$ \\
\hline \multirow[t]{2}{*}{ ATE } & -0.031 & 0.011 & 0.033 & 0.029 & 0.036 & 0.047 \\
\hline & $(0.036)$ & $(0.019)$ & $(0.022)$ & $(0.039)$ & $(0.042)$ & $(0.031)$ \\
\hline \multicolumn{7}{|c|}{ Possession of immunization card } \\
\hline \multirow[t]{2}{*}{ ATT } & -0.002 & -0.010 & -0.002 & -0.016 & 0.006 & 0.000 \\
\hline & $(0.007)$ & $(0.010)$ & $(0.007)$ & $(0.010)$ & $(0.008)$ & $(0.010)$ \\
\hline \multirow[t]{2}{*}{ ATC } & -0.005 & 0.002 & 0.003 & -0.005 & 0.017 & 0.000 \\
\hline & $(0.011)$ & $(0.011)$ & $(0.007)$ & $(0.012)$ & $(0.020)$ & $(0.005)$ \\
\hline \multirow[t]{2}{*}{ ATE } & -0.004 & -0.003 & 0.001 & -0.011 & 0.014 & 0.000 \\
\hline & $(0.008)$ & $(0.008)$ & $(0.006)$ & $(0.008)$ & $(0.014)$ & $(0.006)$ \\
\hline Number of observations & 2,872 & 2,452 & 5,324 & 1,831 & 1,597 & 1,896 \\
\hline
\end{tabular}

ATC: average effect on the comparison group; ATE: average treatment effect; ATT: average effect on the treated.

Note: robust standard error in parenthesis.

Source: authors' calculation using data from the research AIBF (Centro de Desenvolvimento e Planejamento Regional)

SCIENCE - Associação Científica ${ }^{14}$ ).

* Significant at $10 \%$.

nization coverage is quite different depending on the indicator considered. Taking into account the whole immunization schedule in Brazil, the proportion of the population vaccinated is around $77 \%$, whereas $85 \%$ possess the immunization card. Considering only children up 6 month of age, immunization performance is much better. Around $90 \%$ of these children have had all shots on-schedule. This is an interesting indicator as the immunization schedule is more intense for children under 6 months of age and the mother has greater availability to take care of the child during this time. In this case, it is reasonable to assume that the opportunity cost of taking the child to the healthcare center is lower, given that, prior to 6 months of age, most of the mothers have not yet returned to the labor market. A comparison between this indicator and the one regarding all the vaccines reveals that difficulties with maintaining the immunization calendar on schedule occur after 6 months of age. Finally, the proportion of children with at least $70 \%$ of vaccines required up to 6 months of age is quite high, reaching $98 \%$ in the Southeastern region and $95 \%$ for Brazil as a whole.

The analysis of matching quality highlighted some differences between beneficiaries and non-beneficiaries. In general, the indicators for the "Beneficiary" group are always worse than the ones for the "Non-Beneficiary" group, which 
Average effect of the Bolsa Família Program on the immunization of children aged 0 to 6 years, by age group. Brazil, 2005.

\begin{tabular}{|c|c|c|c|}
\hline \multirow[t]{2}{*}{ Result variable } & \multicolumn{3}{|c|}{ Conditioned to male and female guardian schooling considering } \\
\hline & Children aged 0-6 & $\begin{array}{l}\text { Children aged 5-6 } \\
\text { that weren't working }\end{array}$ & $\begin{array}{l}\text { Children aged } 6 \text { that } \\
\text { weren't working and } \\
\text { were studying }\end{array}$ \\
\hline \multicolumn{4}{|l|}{ Vaccination on schedule } \\
\hline \multirow[t]{2}{*}{ ATT } & -0.016 & 0.077 & 0.144 \\
\hline & $(0.050)$ & (0.099) & $(0.246)$ \\
\hline \multirow[t]{2}{*}{ ATC } & 0.045 & 0.125 & 0.174 \\
\hline & $(0.063)$ & $(0.106)$ & $(0.170)$ \\
\hline \multirow[t]{2}{*}{ ATE } & 0.012 & 0.097 & 0.149 \\
\hline & $(0.044)$ & $(0.078)$ & $(0.201)$ \\
\hline \multirow{2}{*}{\multicolumn{4}{|c|}{$\begin{array}{l}\text { All the required shots up to } 6 \text { months } \\
\text { of age on schedule }\end{array}$}} \\
\hline & & & \\
\hline \multirow[t]{2}{*}{ ATT } & -0.024 & -0.008 & -0.034 \\
\hline & $(0.037)$ & $(0.047)$ & $(0.091)$ \\
\hline \multirow[t]{2}{*}{ ATC } & 0.009 & 0.057 & 0.113 \\
\hline & $(0.052)$ & $(0.063)$ & $(0.104)$ \\
\hline \multirow[t]{2}{*}{ ATE } & -0.009 & 0.019 & -0.006 \\
\hline & $(0.034)$ & $(0.040)$ & $(0.085)$ \\
\hline \multicolumn{4}{|c|}{ Possession of immunization card } \\
\hline \multirow[t]{2}{*}{ ATT } & 0.001 & -0.003 & -0.006 \\
\hline & $(0.009)$ & $(0.019)$ & $(0.024)$ \\
\hline \multirow[t]{2}{*}{ ATC } & 0.010 & 0.003 & - \\
\hline & $(0.016)$ & $(0.020)$ & - \\
\hline \multirow[t]{2}{*}{ ATE } & 0.005 & -0.001 & -0.005 \\
\hline & $(0.009)$ & $(0.015)$ & $(0.018)$ \\
\hline Number of observations & 1,564 & 503 & 167 \\
\hline
\end{tabular}

ATC: average effect on the comparison group; ATE: average treatment effect; ATT: average effect on the treated. Note: robust standard error in parenthesis.

Source: authors' calculation using data from the research AIBF (Centro de Desenvolvimento e Planejamento Regional) SCIENCE - Associação Científica 14).

reflects the program's target. For Brazil, "Beneficiary" children usually live in municipalities with high infant mortality rates and lower economic development, being part of households with less-educated male guardians. Even though the matching does not allow us to reduce all differences between beneficiaries and non-beneficiaries, it is important to understand the direction of bias in our control group.

In order to perform a robustness analysis, we add two empirical exercises. In the first exercise we re-estimated our models, restricting our sample to households in which both male and female guardians have no more than four years of schooling. We performed this estimative model in order to control the information bias as both beneficiaries and non-beneficiaries live in households with the same level of information. In the second test, we re-estimated our model considering the restricted sample, but we additionally included only children that were fulfilling education requirements. Our intention with this empirical exercise was to provide a control for the household decision to not enroll in the Bolsa Família Program due to education conditionalities.

Table 3 demonstrates these estimations. The first column refers to the estimation when we considered all children aged 0 to 6 years as living in households in which male and female guardians have no more than four years of schooling. In accordance with our previous result, we did not observe any difference between beneficiaries and non-beneficiaries. The second and third col- 
umns refer to the estimated effects when we controlled the information bias and included only children that were fulfilling education requirements. Furthermore, we did not observe any effect on the immunization profile of the Bolsa Família Program beneficiaries. These results are very significant. In all estimations, we do not observe any difference.

As such, the main results suggest that the Bolsa Família Program did not influence the immunization condition of children in 2005, despite the fact that fulfillment of the immunization schedule, as defined by the Brazilian Ministry of Health, was one of the program conditionalities.

Finally, it is worth mentioning that, throughout our analysis, we had to deal with a severe limitation of the database: the absence of longitudinal information. A longitudinal database or, at least, information pre and post-program would certainly have improved our identification strategy. Thus, future research will depend upon the availability of a longitudinal database as well as a choice of other methodological approaches such as IV estimation and non-parametric evaluation methods.

Although we are aware of the strength of some of the assumptions that we have made in our empirical analysis, at the very least, our paper contributes to shedding some light on the relationship between conditionalities and health program effects.

\section{Resumo}

Este artigo investiga os impactos do Programa Bolsa Família na imunização de crianças de 0 a 6 anos no Brasil e grandes regiões. O Bolsa Família é um programa de transferência condicional de renda. Uma das condicionalidades do Programa Bolsa Família é a atualização do calendário vacinal preconizado pelo Ministério da Saúde. A avaliação é realizada utilizando a técnica do Matching com escore de propensão. Os dados utilizados são da pesquisa conduzida em 2005 para avaliar o programa Pesquisa de Avaliação de Impacto do Programa Bolsa Família. Os principais resultados mostram que o Bolsa Família não afetou o status de imunização das crianças em 2005.

Renda; Políticas Públicas; Imunização; Criança

\section{Contributors}

M. V. Andrade contributed with the estimation of the models, data analysis and drafting of this article. F. Chein contributed with the estimation of the econometric models, result analysis and writing the final draft. L. R. Souza contributed with the organization of the data bank, estimation and analysis of the models and drafting and final revision of the article. J Puig-Junoy contributed revising the paper and writing the final version of this article.

\section{Acknowledgments}

This research was supported by the Brazilian Social Development Ministry [Ministério do Desenvolvimento Social e Combate à Fome/Secretaria de Avaliação e Gestão da Informação (MDS/SAGI)] through the International Technical Cooperation Agreement of the United Nations Program for Development (UNPD) - BRA04-046. 


\section{References}

1. Ministério da Saúde. Programa Nacional de Imunização. http://www.saude.gov.br (accessed on 11/Oct/2007).

2. Paes de Barros R, Mendonça R, Santos DD, Quintaes G. Determinantes do desempenho educacional no Brasil. Rio de Janeiro: Instituto de Pesquisa Econômica Aplicada; 2001. (Texto para Discussão, 834).

3. Kassouf AL. A demanda de saúde infantil no Brasil por região e setor. Pesquisa e Planejamento Econômico 1994; 24:235-60.

4. Guimarães TMR, Alves JGB, Tavares MMF. Impacto das ações de imunização pelo Programa Saúde da Família na mortalidade infantil por doenças evitáveis em Olinda, Pernambuco, Brasil. Cad Saúde Pública 2009; 25:868-76.

5. Juliano Y, Compri PC, Rabello de Almeida L, Freire PV, Moreira FT, Vieira FHS, et al. Segunda etapa da Campanha Nacional de Multivacinação do município de São Paulo, 2005: perfil de cobertura de diferentes Unidades Básicas de Saúde. Rev Paul Pediatr 2008; 26:14-9.

6. Moura da Silva AA, Gomes UA, Tonial SR, Silva RA. Cobertura vacinal e fatores de risco associados à não-vacinação em localidade urbana do Nordeste Brasileiro, 1994. Rev Saúde Pública 1999; 33: 147-56.

7. Janvry A, Sadoulet E. Making conditional cash transfer programs more efficient: designing for maximum effect of the conditionality. World Bank Economic Review 2006; 20:1-29.

8. Lagarde M, Haines A, Palmer N. Conditional cash transfers for improving uptake of health intervention in low-and middle-income countries. JAMA 2007; 298:1900-10.

9. Gertler PJ. Do conditional cash transfers improve child health? Evidence from PROGRESA's control randomized experiment. Am Econ Rev 2004; 94:336-41.
10. Fernaud LC, Gertler PJ, Neufeld L. Role of cash in conditional cash transfer programmes for child health, growth, and development: an analysis of Mexico's Oportunidades. Lancet 2008; 371:828-37.

11. Rocha S. Pobreza no Brasil: o que mudou nos últimos 30 anos? Rio de Janeiro: Instituto Nacional de Altos Estudos e Pesquisas; 2004.

12. Soares S. Distribuição de renda no Brasil de 1976 a 2004 com ênfase no período entre 2001 e 2004. Brasília: Instituto de Pesquisa Econômica Aplicada; 2006. (Texto para Discussão, 1166).

13. Ferreira F, Leite P, Litchfield J. The rise and fall of Brazilian inequality: 1981-2004. Washington DC: World Bank; 2006. (World Bank Policy Research Working Paper, 3867).

14. Centro de Desenvolvimento e Planejamento Regional/SCIENCE - Associação Científica. Coleta de dados (screening e entrevistas) - relatório final. Rio de Janeiro: SCIENCE - Associação Científica; 2005.

15. Lindert K, Linder A, Hobbs J, de la Brière B. The nuts and bolts of Brazil's Bolsa Família Program: implementing conditional cash transfers in a decentralized context. Washington DC: World Bank; 2007. (Social Protection Discussion Paper, 709).

16. Heckman J, Ichimura H, Smith J, Todd P. Characterizing selection bias using experimental data. Econometrica 1998; 66:1017-98.

17. Abadie A, Imbens G. Simple and bias-corrected matching estimators for average treatment effects. Cambridge: National Bureau of Economic Research; 2002. (Technical Working Paper, 283).

18. Rosenbaum PR, Rubin DB. The central role of propensity score in observational studies for causal effects. Biometrika 1983; 70:41-55.

Submitted on 04/Apr/2011

Final version resubmitted on $05 / \mathrm{Jan} / 2012$

Approved on 02/Feb/2012 